\title{
(RE)VALORIZAÇÃO DO TRABALHO: contribuições ergológicas para compreensão do trabalho real
}

\author{
WORK' (RE) VALUE : ergological contributions for understanding real work
}

\author{
(RE) VALOR DEL TRABAJO: contribuciones ergológicas a la comprensión del trabajo \\ real
}

\author{
Naim Rodrigues de Araújo ${ }^{\mathrm{i}}$
}

\begin{abstract}
Resumo: Discute-se aqui os valores do trabalho a partir de sua ontologia perpassando pelos momentos históricos até chegar no estágio atual do capitalismo. A discussão é feita com base em uma abordagem aproximativa entre as contribuições ergológicas e uma revisão bibliográfica a respeito do conceito de trabalho. Têm-se como objetivo neste artigo, sobretudo ampliarmos a ideia de trabalho para além da conotação mercantil que o conceito admitiu no período pós-industrialização. Acreditase que a abordagem ergológica, por compreender o trabalho não apenas do ponto de vista do resultado, mas também do processo, considerando, principalmente as individualidades de cada trabalhador, nos auxilie na retomada de valores não econômicos do trabalho.
\end{abstract}

\begin{abstract}
We discuss here, the values of work from its ontology, going through historical moments until reaching the current stage of capitalism. The discussion is based on an approximate approach between ergological contributions and a bibliographic review regarding the concept of work. The objective of this article is, above all, to expand the idea of work beyond the commercial connotation that the concept admitted in the post-industrialization period. It is believed that the ergological approach, because it understands the work not only from the point of view of the result, but also of the process, considering, mainly the individualities of each worker, helps us to recover non-economic values of work.
\end{abstract}

Resumen: Discutimos aquí los valores del trabajo basados en su ontología, pasando por momentos históricos hasta llegar a la etapa actual del capitalismo. La discusión se basa en un enfoque aproximado entre las contribuciones ergológicas y una revisión bibliográfica sobre el concepto de trabajo. El objetivo de este artículo es, sobre todo, ampliar la idea de trabajo más allá de la connotación comercial que el concepto admitió en el período posterior a la industrialización. Se cree que el enfoque ergológico, porque comprende el trabajo no solo desde el punto de vista del resultado, sino también del proceso, considerando, principalmente las individualidades de cada trabajador, nos ayuda a recuperar valores no económicos del trabajo.

Palavras-chave: Trabalho; Valor; Ergologia.

Keywords: Work; Value; Ergology.

Palabras claves: Trabajo; valor; Ergología. 


\section{INTRODUÇÃO}

Albornoz (2004) retoma os escritos de Marx para dizer que o trabalho humano, compreendido como o ato de planejar antes de executar a tarefa, está paulatinamente desaparecendo, sobretudo pelo avanço da automação industrial e do uso de tecnologias informacionais. À medida que o homem torna-se apenas um executor, sem ao menos imaginar o resultado de suas ações, torna-se um trabalhador alienado. Portanto, para a autora, a extrema divisão do trabalho leva o trabalhador à alienação.

Pois é claro: se já não é possível ao trabalhador conter em sua mente a construção antes de construí-la; se ele está sendo agora incapaz de antever o seu produto em sua totalidade, pois só quem tem a totalidade do produto é a máquina que o trabalhador não domina totalmente, então, o trabalho dos homens está reduzido ao mesmo nível do das abelhas, da agitação animal sem projeto, e logo, desumano. Sem ser dono do projeto do que produz, o homem apenas se agita como as formigas no formigueiro (ALBORNOZ, 2004, p.71).

Albornoz (2004, p.12) diz que "trabalho é o esforço e também o seu resultado: a construção enquanto processo e ação, e o edifício pronto”. Essa definição sintetiza o que pretendemos discutir a seguir: o trabalho no século XXI tem tomado conotações econômicas que nem sempre o entendem em sua complexidade/magnitude, muitas vezes o conceito de trabalho é admitido, de forma limitada, apenas como sinônimo de trocas econômicas ou mercantis.

\section{Trabalho, Emprego e PrecarizaÇão}

Kubo, Gouvêa e Mantovani (2013, p.29) discutem o trabalho para além de fatores econômicos. Os autores entendem que "há uma grande chance de o aspecto econômico não ser o único a ser considerado como essencial do ponto de vista do trabalhador". É preciso compreender as múltiplas dimensões existentes nas relações de trabalho; assim, o trabalho pode ser visto como "forma de se obter a renda, mas também como uma atividade que proporciona realização pessoal, social, meio de se estabelecer e manter contatos interpessoais, entre outros" (GOUVÊA; MANTOVANI, 2013, p.29).

Filho (1994) acredita que para discutir a relação entre o homem e o trabalho é preciso, antes, compreender o significado de Homem. $\mathrm{O}$ autor recorre a antropologia para dizer que o homem é um animal, sendo a racionalidade o fator que o difere dos demais animais. Assim, através de sua racionalidade o homem é capaz de modificar a natureza. Essa transformação é compreendida como sendo o trabalho propriamente dito. Em outras palavras pode-se dizer 
que o trabalho é uma tarefa humanizadora, pois é através do trabalho que o homem produz sua existência/sobrevivência. "O trabalho, essencialmente, é uma ação própria do homem mediante a qual transforma e melhora os bens da natureza, com a qual vive historicamente em insubstituível relação" (FILHO, 2004, p.22).

O autor destaca que ontologicamente o trabalho é gratificante por si só, não sendo necessário atribuir valor de troca para que exista satisfação em realizar um trabalho. "As fontes de dignidade do trabalho devem buscar-se, principalmente, não em sua dimensão objetiva, e sim na sua dimensão subjetiva. O valor do trabalho não reside no fato de que se façam coisas, mas de que são coisas feitas pelo homem” (FILHO, 2004, p.22).

As concepções atuais de trabalho que hipervalorizam as trocas comerciais em detrimento dos valores não mensuráveis produzidos no trabalho nos fazem pensar na necessidade de fazer um investimento para (re)valorizá-lo, sobretudo para retomarmos valores ontológicos que parecem se perder paulatinamente na evolução do sistema capitalista. Para Filho (2004) o aumento significativo na reafirmação de concepções éticas nas organizações empresariais diz respeito, sobretudo, aos valores não financeiros do trabalho que têm sido esquecidos ou sobrepostos pelos valores unicamente financeiros.

“[...] No modo de produção capitalista, o trabalho daqueles desprovidos de propriedade de meios e instrumentos de produção é reduzido à sua dimensão de força-detrabalho" (FRIGOTTO 2008, p. 403). Nessa forma de produção ocorre a redução da compreensão do trabalho para apenas um processo de troca entre empregador e empregado, no qual os donos dos meios de produção determinam as regras e os empregados cumprem em troca de retorno financeiro.

Oliveira e Silveira (2012, p.156) argumentam que, no século XXI, “Trabalho como emprego é pensado não como um ato de afirmação individual, mas de submissão à vontade de outros". Com isso, "Apaga-se, portanto, o processo histórico que até o presente mantém o gênero humano cindido em classes desiguais e que permite a exploração de uns sobre outros" (FRIGOTTTO 2008, p. 403).

No Brasil, os processos de trabalho no modo de produção capitalista, segundo Antunes (2014), convergiram para uma maior exploração da mão de obra, aumento da jornada de trabalho e intensificação do ritmo de produção, visando, sobretudo, aumento da lucratividade. No entanto, esses processos sofreram nova organização a partir da década de 1990, principalmente com a intensificação do uso de tecnologia e com a adoção dos chamados "trabalhos flexíveis". 
[...] a partir de 1990, ampliou-se o processo de reestruturação produtiva, mediante a adoção de novos padrões organizacionais e tecnológicos, de novas formas de organização do trabalho e da introdução dos métodos "participativos", em decorrência das imposições das empresas transnacionais que levaram as suas subsidiárias no Brasil a adotar, em maior ou menor medida, técnicas inspiradas no toyotismo e nas formas flexíveis de acumulação (ANTUNES, 2014, p. 40).

Para Antunes (2012, p. 44) é possível observar no Brasil, sobretudo a partir da década de 1990, "uma nova morfologia do trabalho, caracterizada por sua precariedade estrutural". Para o autor as relações de trabalho têm convergido para uma intensificação da exploração da mão de obra em benefício dos lucros empresariais e em detrimento dos direitos individuais e coletivos da classe trabalhadora. O autor argumenta que a nova morfologia apresenta um discurso de mudança das relações de trabalho e também de flexibilização.

\section{A ERgologia e O CONSTRUCTO dA (RE)VALORIZAÇÃo do TRABALHO}

Schwartz (2006) destaca que a partir da década de 1980, sobretudo com a decadência do modo de produção taylorista, percebeu-se que as teorias estritamente acadêmicas não davam conta de explicar todos os fenômenos que ocorriam no mundo do trabalho, tais como adoecimento e obsolescência. Dentro desse contexto histórico que surgem as preocupações ergológicas: conhecer o "mundo do trabalho" a partir da percepção do próprio trabalhador; refletindo acerca do processo histórico do trabalho e buscando um trabalho conjunto entre teoria e prática.

A abordagem ergológica permite analisar as diferenças entre o trabalho prescrito e o trabalho real. Para Schwartz (2006) o trabalho real sempre será diferente do trabalho prescrito, sobretudo por existir na pratica características próprias do trabalhador. Dentro dessa lógica de apropriação subjetiva das atribuições de um trabalho, percebe-se que um mesmo trabalho concreto pode ter resultados diferentes, mesmo quando os objetivos propostos sejam iguais, sobretudo pelas características individuais de cada trabalhador que o executa, ainda que as diferenças sejam mínimas.

[...] para um mesmo valor de uso, para um mesmo trabalho concreto, podemos encontrar muitas formas de trabalho real, referindo-se a circunstâncias singulares, como, por exemplo, as de fabricação de um prédio (SCHWARTZ, 2006, p.459).

Para o autor, ainda que existam normas, as práticas e características individuais de cada trabalhador se sobressaem às normas, ou pelo menos as reorientam de forma adaptativa às suas características intrínsecas. "O trabalho real, na verdade, é o resultado das 
renormatizações, não dá estrita aplicação e execução das normas. Ou melhor, é a 'execu $\neg$ ção' das normas através das renormatizações" (SCHWARTZ, 2006, p.462).

Schwartz e Durrive (2007) discutem a questão da modificação do trabalho. Hoje o trabalho se apresenta de maneira distinta do que foi no período taylorista, conquanto, o fato de haver maior número de processos automatizados no mundo do trabalho não implica em afirmar que hoje o trabalho é menos degradante, por exemplo. É importante destacar que o trabalho está em constante mudança; mudanças que em termos valorativos representam uma evolução, portanto, podem ser tanto negativas quando positivas. Para concluir acerca do potencial impacto de uma mudança é preciso recorrer mais uma vez a individualidade dos sujeitos, pois para um mesmo processo de trabalho é possível que dois trabalhadores distintos o percebam de forma diferente, sendo, logo, inapropriado fazer previsões de significação das mudanças nos processos de trabalho sem considerar as implicações subjetivas dessas alterações.

Trindade (1997) acrescenta que mesmo diante das exigências impostas ao trabalho concreto; o trabalhador utiliza suas experiências pretéritas, sua história de vida presente e suas perspectivas para o futuro como forma de dar sentido ao seu trabalho e sua relação com o saber.

Dentro dessa nova estruturação do trabalho a ergologia se mostra importante na busca pela compreensão entre o trabalho prescrito e o real, sobretudo por não desconsiderar os conhecimentos tácitos dos trabalhadores, que mesmo não estando escritos ou registrados, implicam diretamente no resultado de suas ações no campo de trabalho.

Trabalhar é sempre uma adaptação individual às regras impostas; cada trabalhador, diante de suas dramáticas, responde de maneira única às regras e normas contidas no campo de trabalho. Trabalhar, portanto, é uma constate "luta" do trabalhador, buscando reorganizar as normas de forma que façam sentido ao seu modo de trabalhar. Esse constante contraste entre o trabalho imposto e o trabalho praticado Schwartz e Durrive (2007) chamam de “dramáticas do uso de si”.

Um drama é estabelecido ao passo que todas as relações de trabalho são dependentes de escolhas. O trabalhador decidi, desde com quais colegas de trabalho terá mais ou menos afinidade até em que medida adotará ou não os procedimentos técnicos prescritos. Essas escolhas estão na dimensão individual, ou seja, é um drama singular para cada trabalhador, que considerará sua subjetividade, seu pensamento de vida, sua experiência pretérita, suas perspectivas de futuro, entre outros fatores, para tomar decisões. Destaca-se, entretanto, que a dimensão individual do trabalho não pode/deve ser vista separadamente da dimensão 
coletiva. Se o trabalho é, pois, uma constante escolha, mais ou menos consciente, há sempre um troca em que o trabalho de um acaba por refletir no trabalho do outro, mais uma vez: de forma mais ou menos consciente.

Schwartz e Durrive (2007) ao falarem do processo de motivação no trabalho, criticam a postura de muitos gestores/gerentes, que, buscando motivar os funcionários, se atentam apenas aos fatores orgânicos, esquecendo-se, no entanto, que a motivação é composta tanto por fatores internos quanto externos.

Não se fala de sociedade, consequentemente não se fala de história, não se fala de política. Fala-se de "ambiente". Tem-se um homem - animal social" - cujo destino, se ele quiser ir bem, tem que estar conforme às normas baseadas na natureza (SCHWARTZ; DURRIVE, 2007, p. 226).

Historicamente o pensamento dominante considera o trabalho apenas como algo árduo, penoso, uma obrigação para sobrevivência. Talvez a partir dessa ideia que emerge a insistente busca por "compensações orgânicas" como forma de motivação no trabalho. "Temos tendência a considerar o trabalho como uma obrigação, como uma necessidade e não como um desejo” (SCHWARTZ; DURRIVE, 2007, p. 229).

É preciso depreender que a satisfação/insatisfação com o trabalho não pode ser interpretada de forma simplista pela relevância social/econômica da profissão. É possível que uma mesma profissão seja entendida como "boa" por alguns e "ruim" por outros. Essa dicotomia é entendida por Schwartz e Durrive (2007, p.234) como “o enigma da atividade".

Trinquet (2010, p.96) nos chama atenção para a diferença entre atividade e atividade de trabalho; termos comumente confundidos como sendo sinônimos. A atividade "é o que se passa na mente e no corpo da pessoa no trabalho, em diálogo com ela mesma, com o seu meio e com os "outros". Ou seja, quando falamos de atividade estamos nos referindo a algo extremante particular, relacionado diretamente com o corpo-si.

Para facilitar a compreensão das diferenças entre os termos, Trinquet (2010) cita, como exemplo, a resposta dada por um assalariado sobre sua atividade; é quase uníssono ouvir, nos relatos dos trabalhadores, uma descrição do seu trabalho prescrito, e não exatamente suas atividades realizadas. Em outras palavras, relata-se as tarefas e não as atividades.

Schwartz (1996) discute o valor atribuído ao trabalho. É inevitável citar, nesse contexto, a ampla concepção de valor relacionada ao salário, sendo, portanto, uma concepção de valor relacionada a troca da força de trabalho por meios de sobrevivência. "O pagamento monetário do trabalho não é em nada um modelo para uso do gênio humano: 
atualmente, contudo, ele é sempre um sintoma e aposta de compromissos, entrelaçados no conjunto de gestões e escolhas sociais" (SCHWARTZ, 1996, p. 154). O autor deixa claro que este valor atribuído ao dinheiro é na verdade um reflexo de uma série de escolhas sociais. $\mathrm{O}$ valor no trabalho, para Schwartz, está para além do valor econômico, "os valores que não são de mercado, e, entre eles, o "bem comum", são presentes, operantes, eficazes, mesmo se pouco aparentes, nas atividades reguladas pelo dinheiro e alocações de recursos" (SCHWARTZ, 1996, p. 153).

Schwartz e Durrive (2016) discorrem a respeito de sempre haver, nas mais diversas atividades dos seres humanos, uma dimensão dramática, não no sentido de ser sempre um drama, mas argumentam que mais ou menos conscientemente, toda atividade requer uma soma de esforços individuais na compreensão e tomada de decisão em todas as atividades. "Falar da dimensão dramática da atividade não significa que cada agir seja semeado de dramas, significa que nada pode ser mecânico" (SCHWARTS, DURRIVE, 2016, p. 326)

Os autores discorrem acerca da importância dos processos de normalização e renormalização. É preciso que saibamos que os processos não são exatamente opostos, embora sejam compreendidos dessa forma em algumas situações.

Nenhuma norma é puramente técnica, e por isso mesmo, neutra, evidente (foram precisos anos, lutas e vidas humanas para codificar os riscos biológicos do amianto). Ao contrário, raramente hoje uma norma é apenas socialmente opressora. A simplificação mutilante começa quando se pretende reduzir a norma a partir de um único de seus polos: o obscuramente, quando se denuncia unilateralmente a vontade de normalizar; a usurpação, quando se pretende dotar a norma do mesmo caráter de necessidade que existe nas leis naturais (SCHWARTS, DURRIVE, p. 331).

Conforme fora supracitado, uma norma tende a não ser apenas opressora, o que significa dizer que as normas geralmente são socialmente aceitas. Em uma sociedade é natural que valores sejam regulamentados, sobretudo para garantir que haja um bom convívio. Conquanto, o fato de uma norma ser reconhecida socialmente não impede que ela possa ser discutida, criticada e reinterpretada individualmente e/ou coletivamente. Assim, depreendese que tanto a normalização quanto a renormalização são, também, resultado de uma reflexão axiológica, são processos naturais que podem ser concorrentes, mas também podem ser complementares. "O elo da norma é, portanto, necessário; a normalização é uma conquista de toda a sociedade humana" (SCHWARTS, DURRIVE, p. 331).

Toda norma sofre influência de um determinado contexto; isso se aplica tanto a regras gerais como as regras sociais que estão sujeitas a interferências de momentos políticos 
e históricos, por exemplo, e também se aplica a regras específicas, como as regras de uma empresa que dependem da visão do gestor, dos recursos estruturais e econômicos da empresa, por exemplo. Ainda que as normas sejam pensadas para atender a demandas específicas, com o passar do tempo podem surgir novas demandas, ou até mesmo as demandas antigas podem ser influenciadas (ressignificadas) por fatos novos, o que torna impossível prever o resultado de aplicação de uma norma. Essa dificuldade de estabelecer resultados prévios resulta em uma tendência à renormalização. "Portanto, a tendência à renormalização é um fato universal porque, de um lado, a exaustiva antecipação, a partir das normas antecedentes, é impossível (SCHWARTS, DURRIVE, p. 333).

Normalizar quando há um vazio de normas, renormalizar quando é preciso ajustar ou não respeitar determinada esfera de normas antecedentes supõe que os protagonistas das escolhas dialoguem, explícita ou implicitamente, com um universo de valores já estabelecidos (SCHWARTS, DURRIVE, p. 337).

Uma aceitação de normas antecedentes, portanto, também resulta de um jogo de valores interno. Há que se pensar que a dimensão humana está e sempre estará presente. Essa reflexão axiológica individual e também coletiva é algo que nem mesmo as instruções normativas às máquinas conseguem substituir a atuação humana, pois cada situação de trabalho se torna única à medida que os sujeitos envolvidos no processo são únicos.

\section{CONSIDERAÇÕES FINAIS}

Espera-se que a discussão aqui apresentada contribua para ampliarmos a compreensão do trabalho, sobretudo no contexto do século XXI, no qual se percebe, conforme bibliografia discutida, supremacia dos valores econômicos do trabalho em detrimento de valores não mensuráveis. Depreende-se que o trabalho é mercantil, mas não apenas isso; depreende-se que o trabalho é labor, mas não apenas isso.

Admitindo que o trabalho transforma-se ao longo da história, e que isso acontece devido a uma série de fatores, como os econômicos e sociais, acredita-se que as contribuições ergológicas suscitem um olhar, no contexto atual, para a necessidade de ampliarmos e (re)valorizarmos o conceito de trabalho, retomando concepções ontológicas, sobretudo por entendê-lo como uma atividade humana complexa.

À medida que ampliamos as concepções de valores no trabalho, compreendendo-as como mensuráveis, mas não apenas isso, podemos angariar recursos para avançarmos nas discussões pertinentes ao momento atual do trabalho. 
Acredita-se que um olhar ergológico, não só para o resultado do, mas, sobretudo, para o humano que realiza o trabalho, nos ajude a compreender/discutir questões que assolam o trabalho moderno, como a insatisfação, desmotivação, absenteísmo e doenças laborais.

Sem a intenção de findar o assunto, acreditamos que o olhar ergológico precisa ser expandido pela sociedade, sobretudo através de pesquisas empíricas, pois estas observações no contexto real prático podem trazer novas discussões a respeito do trabalho, assunto em constante evolução, e que aqui deixamos claro: evoluir significa mudar, não necessariamente para melhor, tão logo, reitera-se a importância de discutir conceitos ontológicos, em busca, sobretudo, de (re)valorizarmos o conceito de trabalho para algo mais amplo que uma simples troca mercantil.

\section{REFERÊNCIAS}

ALBORNOZ, Suzana. O que é Trabalho: 6. ed. São Paulo: Brasiliense, 1994.

ANTUNES, Ricardo. A nova morfologia do trabalho no Brasil: Reestruturação e precariedade. Nueva Sociedad, edição especial, junho, 2012. Disponível em: http://nuso.org/articulo/a-nova-morfologia-do-trabalho-no-brasil-reestruturacao-eprecariedade/. Acesso em: 26, Abr 2019.

ANTUNES, Ricardo. Desenhando a nova morfologia do trabalho no Brasil. Estudos avançados, v.81, n²8, SÃO PAULO, mai/ago, 2014. Disponível em: http:/ / www.scielo.br/scielo.php? script=sci_arttext\&pid=S0103-40142014000200004. Acesso em: 26, Abr 2019.

FILHO, Rubens Miguacclo. Reflexões Sobre O Homem E O Trabalho. Revista de Administração de Empresas, São Paulo, v. 34, n. 2, p. 18-32, Mar./Abr., 1994.

FRIGOTTO, Gaudêncio. Trabalho. In: PEREIRA, Isabel Brasil; LIMA, Júlio César França. (Org.). Dicionário da educação profissional em saúde. 2.ed. rev. ampl. - Rio de Janeiro: EPSJV, 2008. p. 399-404.

KUBO, S, H; GOUVÊA, M, A; MANTOVANI, D, M, N. Dimensões Do Significado Do Trabalho E Suas Relações. PRETEXTO, Belo Horizonte, v. 14, n. 3, p. 28 - 49 jul./set., 2013.

OLIVEIRA, M, C, L; SILVEIRA, S, B. O(s) sentido(s) do trabalho na contemporaneidade. VEREDAS ON-LINE, Juiz de Fora, v. 1, p. 149-165, jan/jul., 2012.

SCHWARTZ, Yves. A comunidade Científica Ampliada e o Regime de Produção de Saberes. Tradução SANTOS, E, E; CUNHA, D. Trabalho e Educação, Belo Horizonte: NETE, n,7, jul-dez, p. 38-46, 2000. 
SCHWARTZ, Yves. Manifesto Por Um Ergoengajamento. In: SHWARTZ, Y; DURRIVE, L (org). Trabalho e Ergologia II: diálogos sobre a atividade humana. Belo Horizonte:

Fabrefactum, p. 325-369, 2016.

SCHWARTZ, Yves. Trabalho e uso de si. Pro-posições, v. 1, nº5, Julho, 2000.

SCHWARTZ, Yves. Trabalho e valor. Tempo Social, Rev. Sociol. USP, S. Paulo, v8, n², p. 147-158, outubro, 1996.

SCHWARTZ, Yves; DURRIVE, Louis. Trabalho \& Ergologia: conversas sobre a atividade humana. 1. ed. Rio de Janeiro: Editora EDUFF, 2007.

SCHWARTZ. Yves. Entrevista. In Trabalho, Educação e Saúde. RJ: Fiocruz, v.4, n 2, p. $457-466,2006$.

TRINDADE, Valter. Trabalho Prescrito e Real no Atual Mundo do Trabalho. Trabalho e Educação, nº1, fev/jul, Belo Horizonte, 1997.

TRINQUET, Pierre. Trabalho E Educação: O Método Ergológico. Revista HISTEDBR On-line, Campinas, número especial, p. 93-113, ago, 2010. Disponível em: http://www.histedbr.fe.unicamp.br/revista/edicoes/38e/art07_38e.pdf. Acesso em: 25, ago. 2018.

\footnotetext{
i Mestre em Educação e Docência pela UFMG. Atualmente é técnico administrativo em Educação na UFMG. Desenvolve pesquisas relacionadas às temáticas: inclusão de pessoas com deficiência, Trabalho e Educação. Email: naim@ufmg.br
} 